\title{
IMPACT OF PARASITE SYMPATRY ON THE GEOGRAPHIC MOSAIC OF COEVOLUTION
}

\author{
Christine A. JOHnSON ${ }^{1}$ AND JOAN M. Herbers \\ Department of Evolution, Ecology and Organismal Biology, The Ohio State University, Aronoff Laboratory,
} 318 W. 12th Avenue, Columbus, Ohio 43210 USA

\begin{abstract}
Slave-making ants are specialized social parasites that steal the young from colonies of their host species to augment their slave supply. The degree of parasite-host specialization has been shown to shape the trajectory along which parasites and hosts coevolve and is a prime contributor to the geographic mosaic of coevolution. However, virtually nothing is known about extrinsic influences on parasite-host dynamics, although the simple addition of a competing slave-maker may significantly alter selection pressures. Here we report the effect of two sympatric slave-makers on a single host. We measured temporal and spatial changes in colonies of the primary host Temnothorax curvispinosus that had been placed in field enclosures along with a single colony of either one or both species of the North American slave-making ants Protomognathus americanus and Temnothorax duloticus. Each slave-maker species alone had a negative impact on its hosts, although one slave-maker species more frequently decimated its host assemblage and then went extinct. Nevertheless, the combined effect in mixed-parasite enclosures was, surprisingly, greatly attenuated. Virulent slave-maker growth and prudent slave-maker decay in these shared enclosures, together with field data showing an inverse proportional relationship between the two slave-makers in natural populations, suggest that their checkered distribution is a consequence of direct asymmetrical antagonism between parasites. Thus, our results imply a tripartite coevolutionary arms race, whereby intraguild interactions among social parasites strongly affect the realized selection pressures on hosts and contribute to the geographic mosaic of coevolution.
\end{abstract}

Key words: competition; geographic mosaic of coevolution; interference effects; intraguild interactions; Protomognathus americanus; slave-making ants; Temnothorax curvispinosus; Temnothorax duloticus; Temnothorax minutissimus.

\section{INTRODUCTION}

The importance of parasites in evolutionary biology and ecology has long been implicit (Price 1980) and parasitologists, evolutionary biologists, and ecologists have made considerable advances in comprehending coevolutionary dynamics between parasites and hosts. The coevolutionary "arms race" (Dawkins and Krebs 1979) and Red Queen phenomenon (Van Valen 1973) have proven to be useful metaphors to describe the reciprocal evolution of parasite virulence and host defense, particularly with respect to simple, single-host systems (Anderson and May 1991). Interspecific interactions, however, are seldom uniform throughout a species' range, and reciprocal selection between parasite and host may be strong in some locations (a "hotspot" of coevolution) but imperceptible in others (a "cold-spot" of coevolution) (Thompson 1994, 1999). This spatial heterogeneity in parasite-host species interactions, or geographic mosaic of coevolution, is driven by rates of gene flow, genetic drift, and extinction/colonization dynamics, as well as by differential

Manuscript received 21 July 2005; revised 9 September 2005; accepted 21 September 2005. Corresponding Editor: D. H. Feener, Jr.

${ }^{1}$ E-mail: johnson.2746@osu.edu selection among populations as a function of diverse community structures (Thompson 1994, 1997, Gandon and Michalakis 2002). Consequently, understanding local hierarchical interactions across a species' geographic range is crucial for understanding coevolution (Thompson 1994, 1997).

Although interspecific interactions rarely involve only two species, community context has only recently been included in theoretical models and empirical studies to evaluate coevolutionary trajectories in parasite systems and other model systems of competition (e.g., Benkman 1999, Benkman et al. 2003, Brandt and Foitzik 2004, Gandon 2004). A primary focus has been the effect of multiple-target use on the outcomes of coevolutionary interactions. Generally, interactions involving multiple targets can be unstable because small evolutionary responses by one species can have significant negative consequences for the other species (Holt and Lawton 1994). For example, the ichneumonid parasitoid Venturia canescens maintains relatively stable interactions within a single, lepidopteran-host relationship. Within a two-host relationship, a second host is always driven to extinction (Bonsall and Hassell 1997). In multitarget systems, reciprocal selection is also relaxed because the enemy's opportunity to modify 
its use of target species decreases exposure to selection (Thompson and Pellmyr 1992, Thompson 1999). The evolutionary repercussion of being weakly adapted to multiple target species is the diminished rate and probability of fixing beneficial alleles or purging deleterious ones (Kawecki 1994, 1998, Whitlock 1996). Thus, variation in target species is capable of producing selection mosaics that differ in intensity and have variable coevolutionary outcomes (Thompson 1994, 1999, Thompson and Pellmyr 1992, Gomulkiewicz et al. 2000; e.g., Benkman et al. 2001, Foitzik et al. 2001, Foitzik and Herbers 2001a, Herbers and Foitzik 2002). This is also true for systems with multiple enemies and a single target species (e.g., Wissinger and McGrady 1993, Benkman 1999, Siddon and Witman 2003), but most of these studies focus on the effect of multiple predators on a single prey whereas interactions between parasites are only just emerging as determinants of community dynamics (Poulin 1998). Almost nothing is known about the social parasites that compete for their host species even though the simple addition of competing species is capable of altering a local assemblage (Hölldobler and Wilson 1990).

The social parasites constitute a unique class that siphons energy from their hosts by diverting behavioral attention such as brood care, feeding, and grooming towards themselves rather than feeding on host organs (Wilson 1971). Because they tend to lack the larger population sizes typical of most other parasites and are relatively rare in community assemblages, the impact of social parasites on host populations had been largely underestimated (Gladstone 1981, Herbers 1986, Davies et al. 1989). However, recent studies show that avian brood parasites can significantly reduce lifetime reproductive output of their heterospecific hosts, sometimes even threatening host populations (e.g., Rothstein and Robinson 1994, Lotem and Rothstein 1995). Hymenopteran social parasites show similar impacts on host populations (Herbers and Stuart 1998, Foitzik et al. 2001, 2003, Foitzik and Herbers 2001a, Hare and Alloway 2001, Herbers and Foitzik 2002, Blatrix and Herbers 2003). Often within the same class as their host, if not closely related phylogenetically (Emery's rule; Emery 1909), social parasite-host systems are more susceptible to cyclical reciprocal selection dynamics compared to micro- and macroparasites and have become a new model system for host-parasite coevolution (Rothstein 1990).

Of the hymenopteran social parasites, slave-making ants are the best studied and are notorious for ransacking colonies of other ant species to acquire brood supplies that will ultimately become a functional work force in the slave-maker colony (Hölldobler and Wilson 1990). Dulosis, or slave-making, has evolved at least nine times between the Formicinae and Myrmicinae subfamilies (Buschinger 1986, Hölldobler and Wilson 1990), and the myrmicine tribe Formicoxenini is particularly rich in slave-maker species. The formicox- enines are small ants both physically and in terms of colony size. Entire colonies are often found within a single acorn or hickory nut or small twig, although it is not uncommon for single colonies to occupy more than a single nest site (polydomy) (Alloway et al. 1982). Three of the four most common formicoxenine slave-makers in North America are known to parasitize more than one host species, sometimes concurrently. Two of these (Protomognathus [= Harpagoxenus] americanus (Emery) and Temnothorax duloticus (Wesson)) are widely distributed in deciduous forests throughout the northeastern United States and Canada. Both are obligate social parasites that share three closely related host species in the genus Temnothorax as their host (Talbot 1957, Alloway 1980, Alloway et al. 1982). (These species, including T. duloticus, have been recently transferred from the genus Leptothorax [Bolton 2003].) P. americanus is more common and better studied than $T$. duloticus and generally considered less fierce, hence more derived, on the basis of their raiding tactics (Stuart and Alloway 1985). $P$. americanus kills fewer adults in raided nests (Wesson 1939, 1940, Alloway 1979) and rears captured sexual brood (Alloway 1979). A field experiment comparing the impact of both slave-makers on different hosts similarly implied the relative severity of $T$. duloticus (Hare and Alloway 2001).

Both $P$. americanus and $T$. duloticus are locally patchy and sometimes occur in sympatry, but nothing is known of their interactions or how these interactions impact a shared host. Here, we present a first study of the interactions between competing slave-makers. We show how a single host species responds under different parasite circumstances and, thereby, assess the individual and combined impacts of each slave-maker. Our results show asymmetric competition between sympatric parasites that has surprising effects on host population dynamics, and is capable of contributing significantly to the geographic mosaic of host-parasite coevolution.

\section{Methods \\ Colony collections}

In fall 2003, we collected and censused the slavemakers Protomognathus americanus and Temnothorax duloticus and their shared host species Temnothorax curvispinosus from several localities within a 15-mile $(\sim 24.2 \mathrm{~km}$ ) radius in central Ohio (Battelle-Darby, Big Run, Highbanks, Prairie Oaks, and Sharon Woods Metro Parks; Alum Creek State Park; Kraus Wilderness Preserve; 4007'31.2" N, 8257'92.3" W). Voucher specimens were deposited in the Museum of Biological Diversity at The Ohio State University.

Our field experiment was conducted during summer 2004 in the mature beech-maple and oak-hickory forest of Kraus Wilderness Preserve where all three species occur. For the experiment, we collected 319 col- 


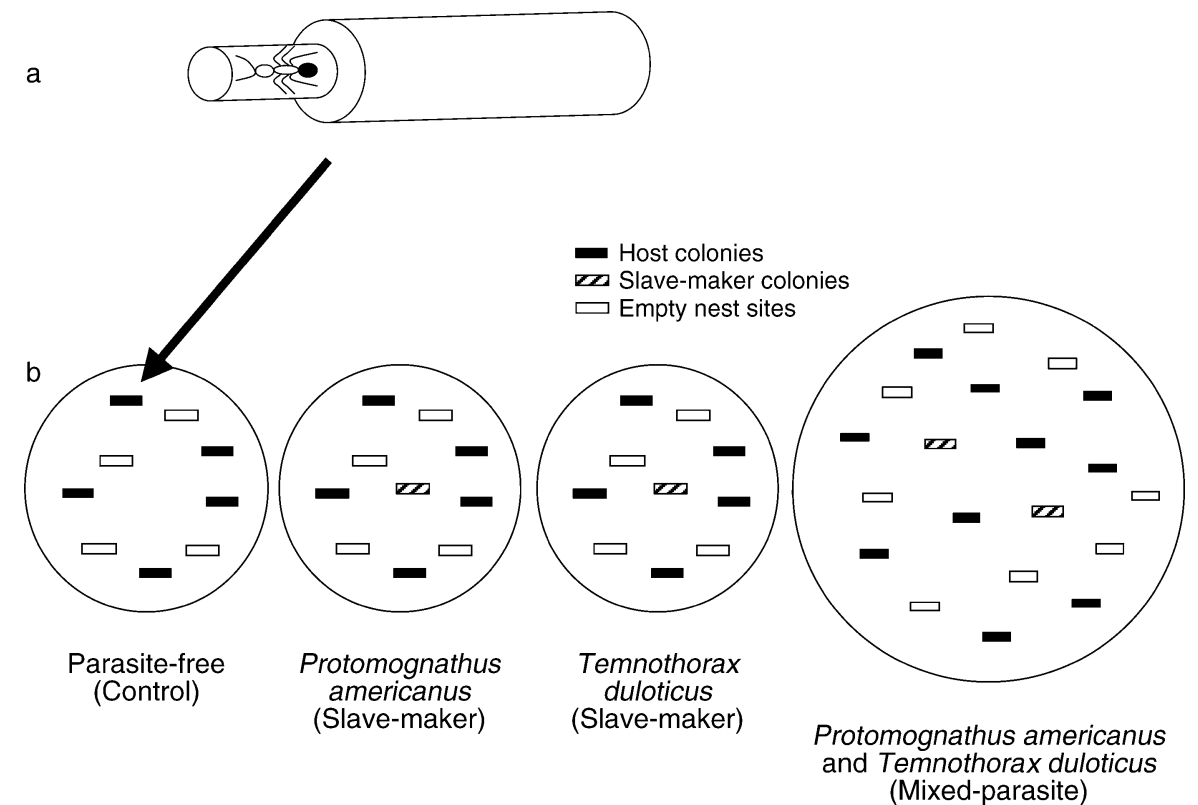

(Mixed-parasite)

FIG. 1. (a) Diagram of a wooden dowel supporting a glass tube in which ant colonies nested. (b) A single block of our experimental design with typical arrangement of colonies in small and large enclosures. Queenless, monogyne, and polygyne colonies of the host species Temnothorax curvispinosus were placed in enclosures that were parasite free or contained a single colony of Protomognathus americanus, a single colony of $T$. duloticus, or a single colony of both slave-maker species. These colonies were censused eight times thereafter throughout a single raiding season. Movement of colonies was extrapolated from the constitution of occupied dowels in conjunction with dowel occupancy in the previous census.

onies of T. curvispinosus, 15 colonies of T. duloticus, and 17 colonies of $P$. americanus from central Ohio in May 2004. These colonies were removed from their natural nests, censused and sorted by queen number $(0$, 1 , or, for host species only, 2-3). Within the monogyne (single-queen) category, host colonies were sorted further by size (small, 17-25 workers; medium, 45-65 workers; large, 75-110 workers). We selected 12 colonies of $T$. duloticus, 12 colonies of P. americanus, and 150 colonies of $T$. curvispinosus for use in our experiment. Host colonies were chosen to give a ratio of one queenless:three monogyne:one polygyne (multiple-queen) colonies with the monogyne category consisting of equal proportions of small, medium, and large colonies. Log-transformed worker numbers in host colonies did not differ by treatment $(\mathrm{df}=3,97)$ or block (df $=5,97)(F<0.55, P>0.78)$. We actively selected parasite colonies from our available pool with the intent of having similar slave-maker and host numbers. Nonetheless, there was an inherent and therefore unavoidable significant difference in the average number of slave-makers per nest between $T$. duloticus and $P$. americanus $(13.3 \pm 8.07$ and $7.8 \pm 7.03$, respectively [mean $\pm \mathrm{SD}$ ]; Kruskal-Wallis $Z=2.35, P<$ 0.05 ). Slave worker (Kruskal-Wallis $Z=0.43, P=$ 0.66 ) and larval (Kruskal-Wallis $Z=0.12, P=0.91$ ) numbers did not differ between slave-maker species. All colonies were settled into glass tubes $(9.5 \mathrm{~cm}$ length, $4 \mathrm{~mm}$ outer diameter), each of which was then inserted into a birch dowel $(10 \mathrm{~cm}$ length) that had been hollowed to accommodate the glass tubing (Fig. 1a). The glass tubes were easily extracted from the dowels, which allowed us to examine the colonies and count the contained inhabitants throughout the experimental period without disturbance.

\section{Experimental design}

Our experimental design was $2 \times 2$ full factorial with six replicates. We constructed 24 circular enclosures in six blocks of four with aluminum flashing submerged approximately $6.5 \mathrm{~cm}$ into ground that had been cleared of acorn and hickory nuts, twigs, and leaves. Three of the four treatment enclosures in each block were "small" in diameter $(1.22 \mathrm{~m})$ and received five T. curvispinosus colonies (one queenless:three monogynous:one polygnous) and (a) no slave-maker, (b) one $T$. duloticus colony, or (c) one $P$. americanus colony. The fourth large enclosure in each block was twice the area of a small enclosure $(1.73 \mathrm{~m}$ in diameter) to accommodate $10 \mathrm{~T}$. curvispinosus colonies and one colony of each slave-maker. The number of host colonies and area in these enclosures were doubled so that slavemakers had equal access to and similar probabilities of encountering host colonies as in small enclosures. We also supplied small and large enclosures with four or eight vacant dowels respectively to provide colonies the opportunity to relocate. Slave-maker colonies were placed at the center in small enclosures and off-center in large enclosures. Fig. 1b depicts one block of our full-factorial experimental design and the general po- 


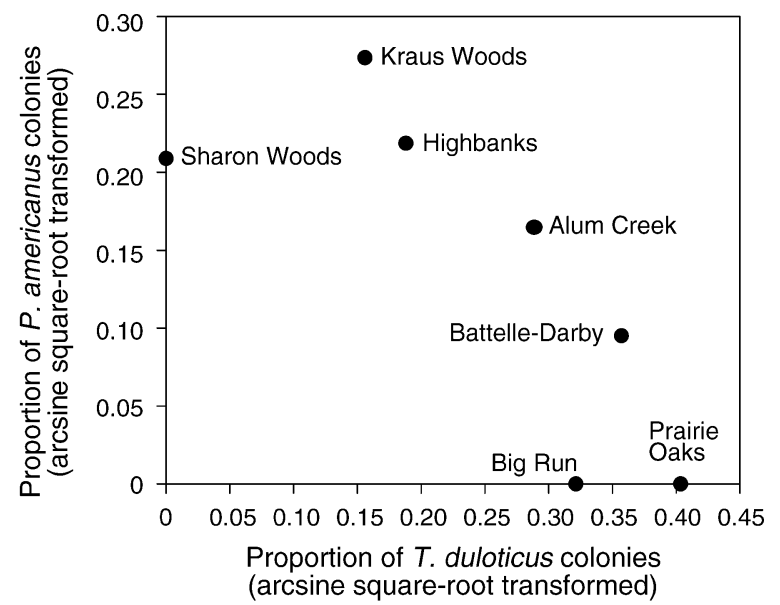

FIG. 2. Slave-maker prevalence (proportion of slave-maker colonies) in seven sites around Columbus, Ohio, USA. As the frequency of one slave-maker increased relative to the host, the other slave-maker species decreased.

sition of host and parasite colonies and empty dowels within enclosures. To prevent colony exodus or the intrusion of other invertebrates, both sides of the enclosure flashing were smeared with a wide band of petroleum jelly. Enclosures were also covered with plastic mesh (mesh size $\left.3 / 4^{\prime \prime} \times 1^{\prime \prime}[\sim 1.9 \times 2.5 \mathrm{~cm}]\right)$, which prevented leaves and sticks from dropping into the enclosures but allowed a rain of natural detritus these scavenger ants typically gather as food sources.

Enclosures were stocked at the end of May 2004. Every two weeks thereafter until 29 September 2004, all dowels were removed from each enclosure, the inhabitants counted, and the dowels returned to their original position within 30-40 h. Each week, one or two tablespoons of frozen Drosophila were sprinkled in each small or large enclosure, respectively, to supplement natural food sources.

\section{Statistical procedures}

Distributions were tested for normality and heteroscedasticity. Data were transformed or analyzed with nonparametric tests when appropriate. Host colony demographics were analyzed using repeated-measures mixed-model ANOVAs with blocks. Treatment and census date were treated as fixed factors and enclosures were treated as the random effect. Demographic data from slave-maker colonies were analyzed as the proportion of original individuals at each census date to account for the natural difference in slave-maker colony size of each species. We used repeated-measures ANOVAs with slave-maker species nested within treatment to account for the presence of both slave-maker species in large enclosures and the absence of the alternative slave-maker in small enclosures. The square roots of percentages were arcsine transformed to normalize the data. Tukey's test for honestly significant differences was used for all pairwise comparisons with an alpha level of 0.05. All analyses were carried out in JMP 4.0.2 (SAS Institute, Cary, North Carolina, USA).

\section{REsults}

\section{Ecological background}

Slave-maker frequencies in central Ohio varied across sites within our "park populations." All these sites contained the host $T$. curvispinosus, but varied in the occurrence and relative proportions of the two slave-makers. Some sites contained only $P$. americanus or only $T$. duloticus whereas other sites contained both or neither. Those sites without slave-makers also tended to have few host colonies, an indication that these habitats could not support parasite populations.

Among park populations, there was a strong inverse relationship in the proportion of each slave-maker species $(r=-0.77, F=7.43$, df $=1,6, P=0.04$; Fig. 2 ), which may be a reflection of exclusionary interspecific parasite interactions. Typically, P. americanus colonies had more slaves per slave-maker than $T$. $d u$ loticus colonies. Regression analyses showed that slave-maker number was not necessarily a good indicator of $P$. americanus raiding force, whereas in $T$. duloticus colonies, slave number increased with slavemaker number (Table 1).

Within Kraus Woods Preserve, colonies of the host T. curvispinosus and the slave-maker $P$. americanus were relatively abundant, making up $91.2 \%$ and $6.9 \%$, respectively, of our collection (Table 2). T. duloticus was less common, making up only $1.9 \%$ of our collection. A greater proportion of T. duloticus colonies were queenright $(64.3 \%)$ than $P$. americanus $(51.9 \%)$; one colony of $P$. americanus contained two queens. Consistent with colonies from other populations, $T$. $d u$ -

TABLE 1. Number of slave-makers and slaves in nests of Protomognathus americanus and Temnothorax duloticus from populations around Columbus, Ohio, USA.

\begin{tabular}{|c|c|c|c|c|c|c|c|}
\hline \multirow[b]{2}{*}{ Slave-maker species } & \multirow{2}{*}{\multicolumn{3}{|c|}{$\begin{array}{c}\text { Mean ratio } \\
\text { slave- } \\
\text { makers : } \\
\text { slaves }\end{array}$}} & \multicolumn{2}{|c|}{ Regression coefficient } & \multicolumn{2}{|c|}{ Intercept } \\
\hline & & & & Mean $\pm \mathrm{SE}$ & $P$ & Mean $\pm \mathrm{SE}$ & $P$ \\
\hline $\begin{array}{l}\text { P. americanus }(n=16) \\
\text { T. duloticus }(n=23)\end{array}$ & $\begin{array}{r}9.8 \pm 1.56 \\
16.19 \pm 0.21\end{array}$ & $\begin{aligned} 104.87 & \pm 11.3 \\
66.24 & \pm 11.25\end{aligned}$ & $\begin{array}{l}1: 11 \\
1: 4\end{array}$ & $\begin{array}{l}0.25 \pm 0.18 \\
0.85 \pm 0.16\end{array}$ & $\begin{array}{c}0.19 \\
<0.0001\end{array}$ & $\begin{array}{l}1.75 \pm 0.17 \\
0.74 \pm 0.19\end{array}$ & $\begin{array}{c}<0.0001 \\
0.001\end{array}$ \\
\hline
\end{tabular}

Note: Regression on log-transformed slave-maker vs. slave number shows that slave-maker numbers in $P$. americanus are poor indicators of slave force. 
TABle 2. Colony demographics of the slave-makers P. americanus and T. duloticus and their shared host T. curvispinosus collected at Kraus Preserve during May and June 2004.

\begin{tabular}{|c|c|c|c|}
\hline Type & $\begin{array}{l}\text { T. duloticus } \\
(n=14)\end{array}$ & $\begin{array}{l}P . \text { americanus } \\
(n=52)\end{array}$ & $\begin{array}{l}\text { T. curvispinosus } \\
(n=689)\end{array}$ \\
\hline \multicolumn{4}{|l|}{ Reproductive caste } \\
\hline Queens, dealate & 9 & 28 & 816 \\
\hline Queens, alate & 0 & 0 & 207 \\
\hline Males & 0 & 81 & 176 \\
\hline Workers & & & $33.76 \pm 23.9$ \\
\hline Slave-makers & $8 \pm 8.6$ & $4.57 \pm 5.6$ & \\
\hline Host & $27 \pm 17.8$ & $32.27 \pm 29.1$ & \\
\hline Larvae & $19.5 \pm 12.1$ & $15.6 \pm 12.9$ & $34.09 \pm 24.8$ \\
\hline Queen pupae & & & 95 \\
\hline Slave-maker & 0 & 0 & \\
\hline Host & 0 & 4 & \\
\hline Worker pupae & & & $13.28 \pm 12.8$ \\
\hline Slave-maker & 0 & 11 & \\
\hline Host & 73 & 316 & \\
\hline Male pupae & & & 237 \\
\hline Slave-maker & 1 & 17 & \\
\hline Host & 0 & 34 & \\
\hline \multicolumn{4}{|l|}{ No. nests (\% total) } \\
\hline Queenless & $5(35.7 \%)$ & $25(48.1 \%)$ & $145(21.2 \%)$ \\
\hline Monogyne & $9(64.3 \%)$ & $26(50.0 \%)$ & $400(58.4 \%)$ \\
\hline Polygyne & 0 & $1(1.9 \%)$ & $140(20.4 \%)$ \\
\hline
\end{tabular}

Note: Single values represent sums; other values are means \pm SD.

loticus tended to have more slave-makers per nest but fewer slaves than $P$. americanus. Aside from colony queens and a single male pupa, there were effectively no sexuals in $T$. duloticus colonies during this time; several of the queenless $P$. americanus colonies, on the other hand, contained males, male pupae, and a few queen pupae. A relatively small number of $T$. curvispinosus colonies had alate females and males, and we found queenless, monogyne, and polygyne nests of $T$. curvispinosus in a 1:3:1 ratio (Table 2).

\section{Direct evidence of social parasitism}

Within three days after enclosures had been stocked, we observed $T$. duloticus raiding in two enclosures. One raid was directed at a monogyne host colony with approximately 69 workers in an enclosure with no other slave-maker. On the next census date (12 June), this dowel was empty. The second observed raiding event was directed against the $P$. americanus colony in the mixed-parasite treatment. Workers of the host species (T. curvispinosus) appeared to be attacking P. americanus adults. This dowel was also empty on the next census date. $P$. americanus were not seen again in this enclosure until the last census date, when a single worker was found in a host colony. These data corroborate reports by other authors (Wesson 1940) that T. duloticus begins raiding earlier in the season than $P$. americanus.

In early July, two monogyne host colonies, each in different enclosures that contained only the T. duloticus slave-maker, were invaded by $P$. americanus queens and stripped of their resident queens. In one colony, the $P$. americanus queen disappeared by the next cen- sus date, whereas in the other colony the P. americanus queen remained for at least four weeks thereafter. These observations indicate mid-summer nuptial flights for $P$. americanus queens followed by new colony establishment that may often fail.

In late August, we discovered one pupa and three alate and two dealate queens of the rare workless parasite, Temnothorax minutissimus, in a queenright $P$. americanus colony. T. minutissimus overwinter as larvae and have extended developmental times (S. Cover, personal communication). This colony was probably parasitized by $T$. minutissimus the previous year. By the next census date, all T. minutissimus disappeared, having either dispersed or been destroyed by inhabitants of the $P$. americanus colonies.

\section{Impact on host populations}

Overall, host colonies in our field enclosures suffered significant losses in worker numbers within the first six weeks after colonies had been placed in enclosures $(F$ $=17.37$, df $=8,12, P<0.001$; Tukey's hsd $Q=3.1$ ), with only about $50 \%$ of workers remaining even in parasite-free enclosures (Fig. 3a). This loss may have been due in part to brief periods of enclosure flooding during June when central Ohio experienced record rainfall. Nonetheless, $T$. duloticus slave-makers with exclusive access to host colonies imposed even greater costs on worker numbers $(F=9.62, \mathrm{df}=3,112, P<$ 0.0001 ; Tukey's hsd $Q=2.61, P<0.05)$. In these enclosures, there were between 25 and $50 \%$ fewer host colony workers within the first two weeks after colonies had been placed in the field. In mixed-parasite enclosures, the impact of $T$. duloticus appears to have been 


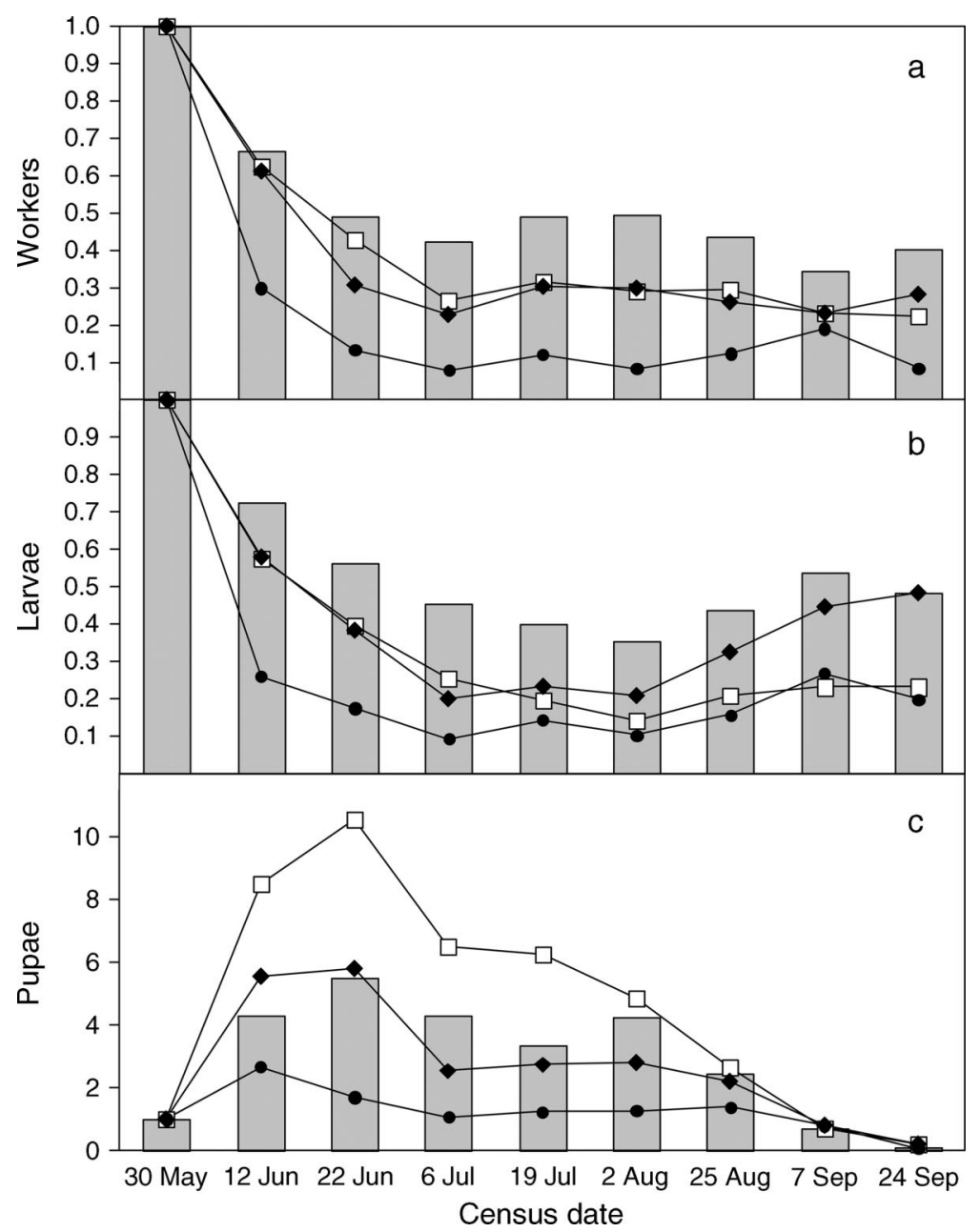

FIG. 3. Impact of single and multiple slave-makers on hosts as indicated by the proportion of the original number of (a) workers, (b) larvae, and (c) pupae remaining in host colonies in each treatment over the 2004 census period. The data for 30 May 2004 represent the total number of individuals in enclosure host colonies standardized to equal a proportion of 1. Shaded histogram bars represent parasite-free enclosures; solid diamonds, enclosures with only P. americanus; solid circles, enclosures with only $T$. duloticus; open squares, mixed-parasite enclosures.

restrained, as these host colonies fared overall no worse than host colonies in parasite-free enclosures or in enclosures with only a $P$. americanus slave-maker (Fig. 3a).

Larval and pupal production in host colonies waxed and waned (Fig. 3b and c) throughout the summer in a typical cyclic fashion of immature development (Hölldobler and Wilson 1990). High larval numbers in host colonies at the end of May decreased steadily throughout the summer and rose slightly again towards the beginning of fall $(F=4.94, \mathrm{df}=7,97, P<0.0001$; Tukey's hsd $Q=3.1, P<0.05$ ). Conversely, low pupal numbers crested in mid to late June and dwindled by early fall $(F=28.34$, df $=7,84, P<0.0001$; Tukey's hsd $Q=3.11, P<0.05)$. In parasite-free enclosures, the early wane in pupae coincided with a slight increase in worker numbers (Fig. 3a and c).

However, immature production was affected differently in different treatments. Host colonies subjected only to $T$. duloticus had the lowest presence of both larvae $(F=5.19$, df $=3,97, P<0.002)$ and pupae $(F=6.49$, df $=3,84, P<0.0005$; Tukey's hsd $Q=$ $2.62, P<0.05$; Fig. $3 \mathrm{~b}$ and c). Although larval numbers were sometimes equally low in mixed-parasite enclosures, pupal numbers were at times almost twice as abundant as in any other treatment, including parasitefree conditions (Fig. 3b and c). This indicates that larval loss in mixed-parasite enclosures was primarily a function of maturation and not necessarily raiding, and again that the impact of T. duloticus was muted when $P$. americanus was also present in the enclosure. $P$. americanus alone had a comparatively lower impact on larval and pupal production in host colonies, although larval numbers sometimes dipped to half that of control assemblages. In $P$. americanus and parasite-free enclosures, larvae declined and pupae surged from early to mid summer and resurged and waned respectively 


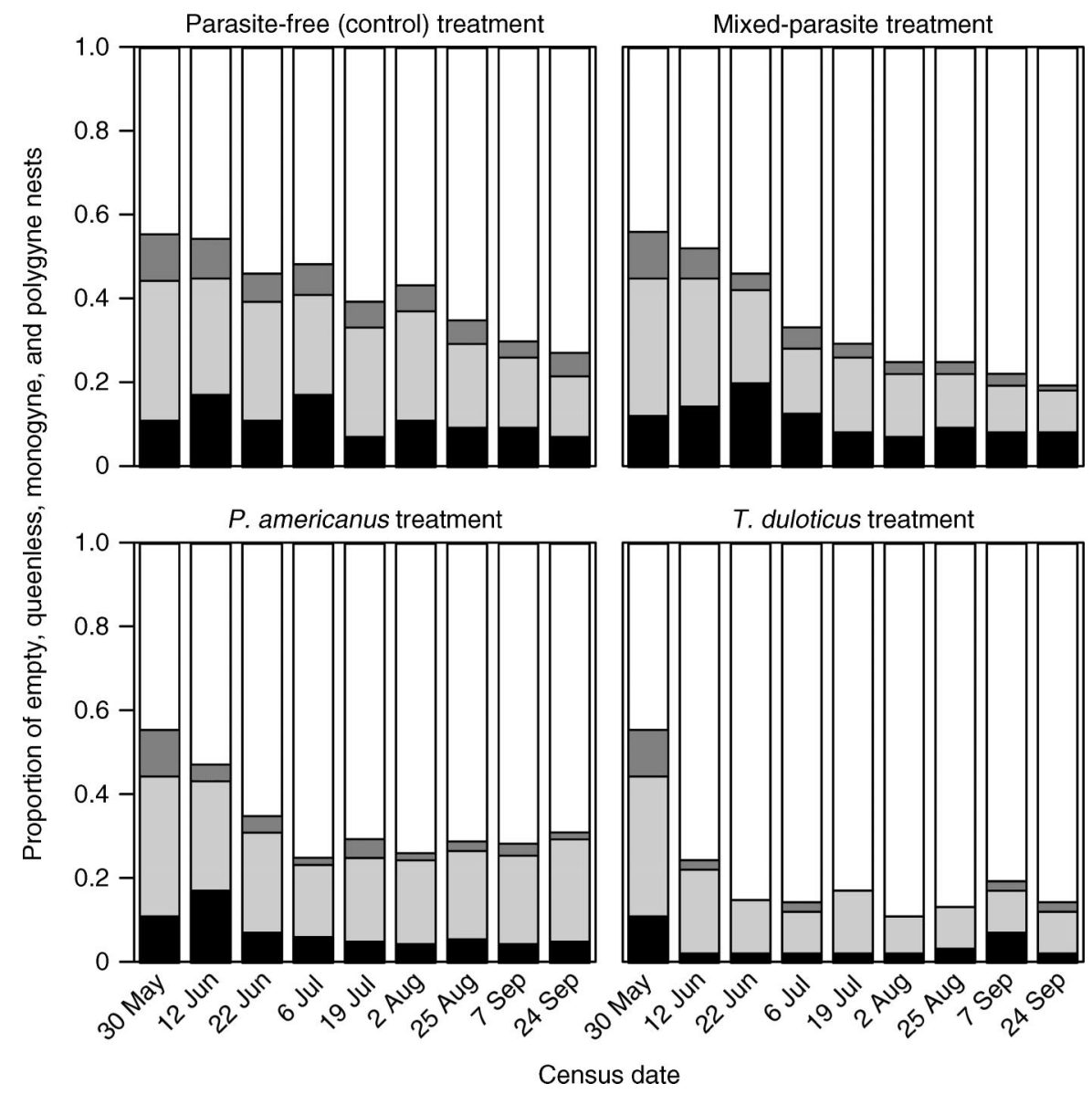

FIG. 4. Host colony queen status from early to late summer in enclosures with no, one, or both slave-makers. For each census date (see Fig. 3), we indicate the proportion of queenless (black bars), monogyne (light gray bars), and polygyne (dark gray bars) colonies, along with vacant nest sites (open bars).

as fall approached, whereas larval production increased minimally in $T$. duloticus and mixed-parasite enclosures after declining (Tukey's hsd $Q=2.614, P<0.05$; Fig. $3 b$ and c). This may be a result of inter-slavemaker dynamics. All enclosures in block 5 had significantly greater numbers of pupae than the other blocks; this is probably because this set of enclosures was not as adversely affected by the temporary flooding during June $(F=3.026$, df $=5,84, P<0.05$; Tukey's hsd $Q=2.92, P<0.05)$.

There was a differential impact on queenless, monogyne, and polygyne host colonies (Figs. 4 and 5). A disproportionate number of polygyne colonies disappeared completely in enclosures with only $T$. duloticus, having either split into single queen fragments or been wiped out by $T$. duloticus (treatment $\times$ queen number interaction: $F=3.38$, df $=3,38, P<0.05$; Tukey's hsd $Q=3.66, P<0.05$; Fig. 4, Appendix A). Monogyne colonies were furthermore the smallest in enclosures with only $T$. duloticus (Tukey's hsd $Q=3.49$, $P<0.05$; Fig. 5). In all other treatments, including the mixed-parasite condition, the proportion of queenless, monogyne, and polygyne nests remained relatively constant throughout the summer (Fig. 4), and worker numbers varied in a fashion that is typical of colonies with different queen numbers $(F=3.54$, df $=6,36$, $P<0.01$; Fig. 5), i.e., polygyne colonies tended to be larger than queenless and monogyne colonies.

\section{Slave-maker colony demographics}

Comparison of slave-maker demography between the single-parasite and mixed-parasite treatments showed that in both treatments, $P$. americanus colonies eventually lost nearly all slave-maker workers (Fig. 6e), as did T. duloticus when alone (Fig. 6a). By contrast, $T$. duloticus in the mixed-parasite enclosures experienced a significant swell in slave-maker numbers in late August $(F=32.88, \mathrm{df}=1,16, P<0.0001$; Fig. 6a). The steepest decline in slave-maker workers occurred in $P$. americanus colonies in mixed-parasite enclosures (Tukey's hsd $Q=3.18, P<0.05$; Fig. 6e).

Slave numbers also declined soon after the start of the experiment and thereafter rebounded only slightly 

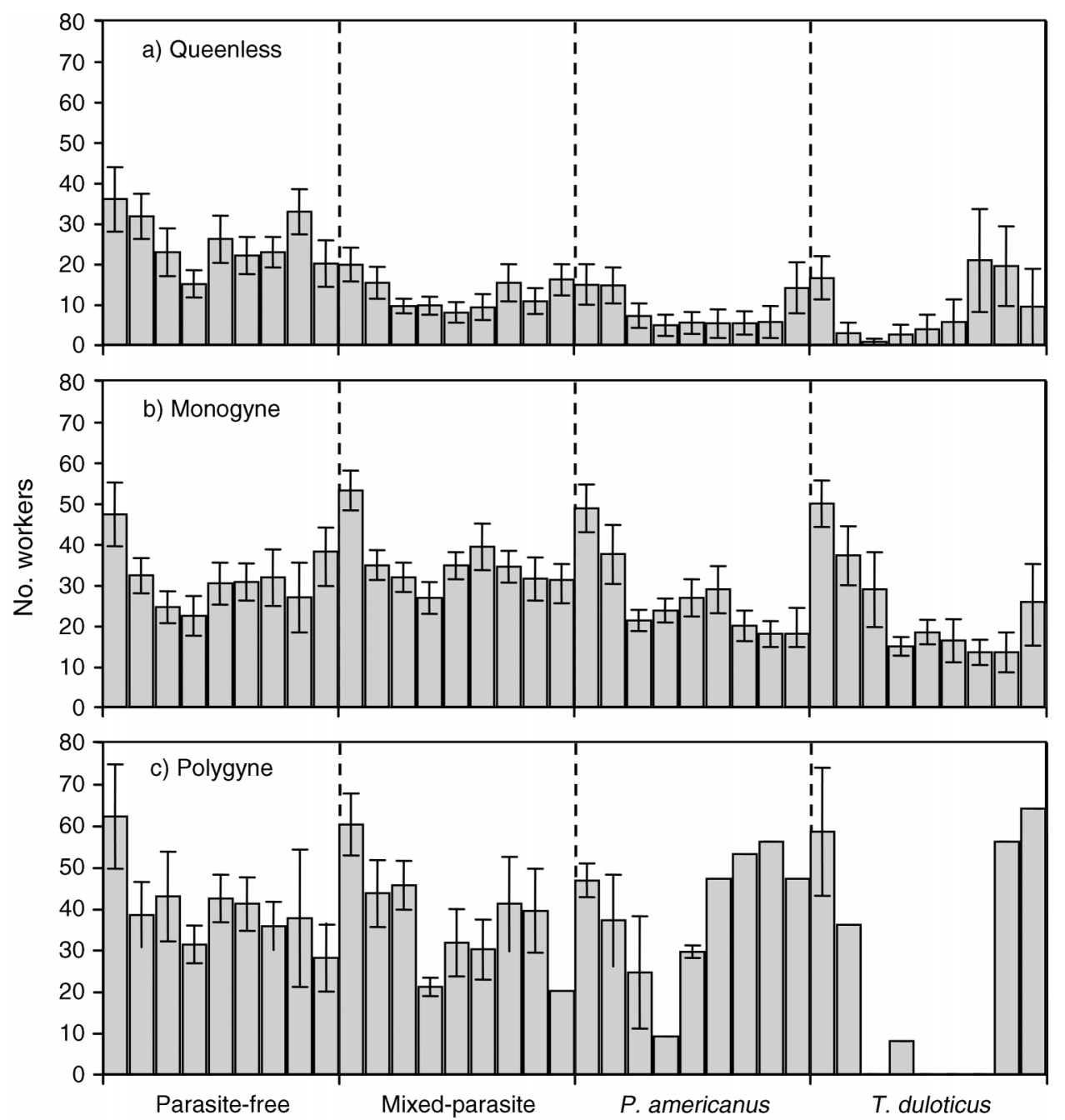

FIG. 5. Impact of single or multiple slave-makers on (a) queenless, (b) monogyne, and (c) polygyne host colonies. Numbers of workers (mean $\pm \mathrm{SE}$ ) are given for each of the four treatments and are ordered by census date within treatment (as in Fig. 3; from 30 May to 24 September 2004).

$(F=29.66, \mathrm{df}=8,16, P<0.001 ;$ Tukey's hsd $Q=$ $3.5, P<0.05$; Fig. $6 \mathrm{~b}$ and $\mathrm{f})$. The most drastic decline in slave numbers $(F=17.6$, df $=1,16, P<0.001)$ as well as in larval numbers (Fig. $6 \mathrm{c}$ and $\mathrm{g} ; F=19.54$, df $=1,16, P<0.0005)$ occurred again in $P$. americanus colonies in mixed-parasite enclosures (Tukey's hsd $Q=3.18, P<0.05$ ); in these same enclosures, $T$. duloticus colonies maintained the greatest proportion of slaves and larvae (Fig. $6 \mathrm{~b}$ and c). In single-parasite enclosures, slave numbers in $P$. americanus and $T$. $d u$ loticus colonies were intermediate and virtually the same for both slave-maker species. The significant drop in larvae numbers early in the summer $(F=4.1$, df $=$ 8, 16, $P<0.01$; Tukey's hsd $Q=3.18, P<0.05)$ coincided with the increase in the log-transformed number of pupae $(F=23.02$, df $=8,16, P<0.0001$; Tukey's hsd $Q=3.5, P<0.05)$ for both slave-maker species in all treatments (Fig. 6d and h). However, al- though all pupae numbers eventually exceeded original amounts, $P$. americanus colonies in mixed-parasite enclosures contained only a small fraction of the pupal numbers found in $T$. duloticus colonies or in $P$. americanus colonies in single parasite enclosures $(F=$ 29.36, df $=1,16, P<0.0001$; Fig. $6 \mathrm{~d}$ and h).

In three of the mixed-parasite enclosures, entire $P$. americanus colonies were displaced by T. duloticus or disappeared altogether within the first month of the experiment, and both slave-makers disappeared within the first six weeks in two replicates. In single-parasite enclosures, $T$. duloticus disappeared completely in four replicates, three of which had already been depleted of host colonies. P. americanus also disappeared from four enclosures in single-parasite treatments, but the loss was restricted to $P$. americanus adults. Continued occupation of these $P$. americanus nest sites by slaves and larvae indicates natural adult attrition accounted 

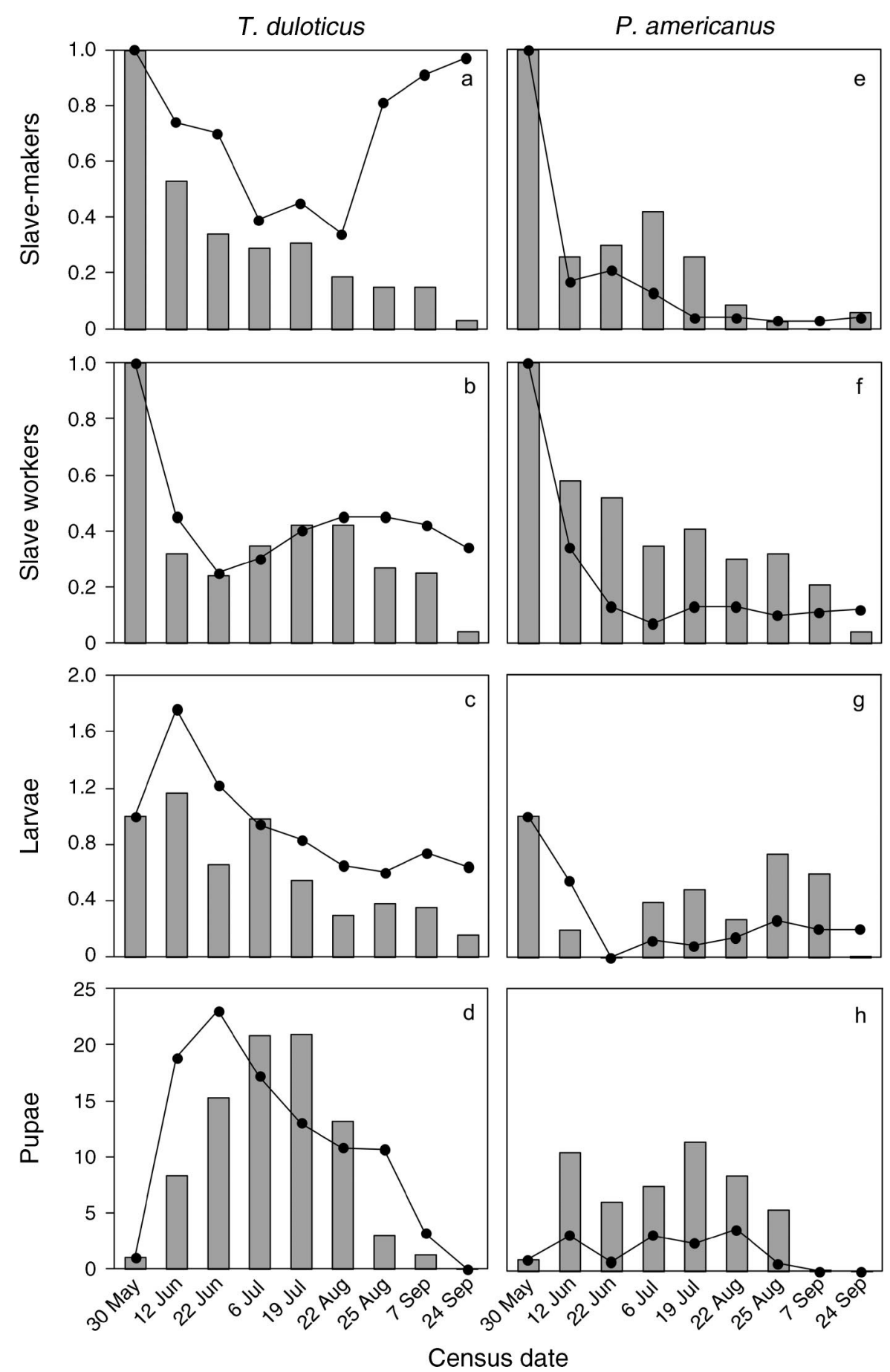

FIG. 6. Success of T. duloticus and P. americanus slave-maker colonies with exclusive (bars) or shared (solid circles) access to host colonies, measured as the proportion of the original number of $(\mathrm{a}, \mathrm{e})$ slave-makers, $(\mathrm{b}, \mathrm{f})$ enslaved host workers, (c, g) larvae, and (d, h) pupae over the census period. Data for 30 May 2004 (first bar) represent the total number of individuals in enclosure host colonies standardized to equal a proportion of 1.

for slave-maker loss. These qualitative differences in slave-maker colony decline or disappearance in conjunction with early $T$. duloticus raiding suggest that, when sympatric, T. duloticus may be at least partly responsible for the loss of nearby $P$. americanus.

\section{Slave-maker occupation and host colony movement}

A summary of the total number of queenless, monogyne, and polygyne host colonies and empty dowels that were invaded by $T$. duloticus and $P$. americanus 
TABLE 3. Prior occupants of nest sites invaded by slavemakers in single- and mixed-parasite enclosures.

\begin{tabular}{lcccrr}
\hline \hline & \multicolumn{3}{c}{ Dowel constitution } & \\
\cline { 2 - 4 } & \multicolumn{3}{c}{ Host colony } & & \\
\cline { 2 - 5 } Queen- & $\begin{array}{c}\text { Mono- } \\
\text { gyne }\end{array}$ & $\begin{array}{c}\text { Poly- } \\
\text { gyne }\end{array}$ & Empty & Total \\
\hline Single-parasite enclosures & & & & \\
T. duloticus & 1 & 2 & 0 & 10 & 13 \\
$P$. americanus & 0 & 0 & 1 & 8 & 9 \\
Mixed-parasite enclosures & & & & \\
$\quad$ T. duloticus & 1 & 3 & 3 & 7 & 14 \\
$P$. americanus & 0 & 0 & 0 & 6 & 6 \\
\hline
\end{tabular}

colonies is provided in Table 3. Colonies of T. duloticus were more likely to move into other dowels than were $P$. americanus colonies regardless of whether $P$. americanus was present in the enclosure or not (likelihood ratio $\left.\chi^{2}=4.59, P<0.05\right)$. Colonies of $T$. duloticus were also more likely than $P$. americanus to occupy previously occupied nests. Even so, $63 \%$ of the dowels T. duloticus occupied had been empty (Likelihood ratio $\left.\chi^{2}=5.36, P<0.03\right)$. These invasion patterns suggest that $T$. duloticus continually changes nest sites and is less discriminating in nest site choice. $P$. americanus, on the other hand, is more sedentary and, if the colony moves, is more likely to occupy an empty nest site.

Overall, host colonies tended to immigrate to new nest sites rather than remain in their initial nest sites (likelihood ratio $\chi^{2}=9.36, P<0.0001$; Fig. 7). Although host colonies in parasite-free enclosures were significantly less likely to move than in any other treatment, only $30 \%$ remained in their original dowels by the last census (likelihood ratio $\chi^{2}=10.77, P<0.05$ ). The rate of host colony movement increased significantly when a single species of slave-maker was also in the enclosure (Fig. 7). When both slave-maker species were present, however, rates of host colony movement only began diverging from movement rates in control enclosures on the sixth week. Eventually, most host colonies in mixed-parasite enclosures also moved (Fig. 7). These results indicate raiding pressure or slave-maker occupation forces host colonies to abandon their nest sites.

\section{Discussion}

Coevolutionary trajectories vary across time and space (Thompson 1994) and extrinsic factors, such as competing predators or parasites, that shape reciprocal selection dynamics are seldom apparent. Nonetheless, it is clear that the prevailing paradigm of a coevolutionary arms race must be broadened and embedded within the context of community-level ecological interactions to fully understand the resulting geographic mosaic. The aim of our study was to understand hostparasite dynamics within various parasite contexts. Our results show that in sympatry parasites had a nonadditive combined impact on their shared host. We had expected accelerated losses of host colonies, as each slave-maker would scramble to secure host resources. Instead, we found the impact on hosts was by all measures either comparable to or less than that of the "weaker" parasite. Our results also confirmed the disparate virulence of the two parasite species that had been implied by Hare and Alloway (2001). Although both slave-makers alone had measurable negative effects on the shared host, host colonies that encountered only $T$. duloticus were oftentimes simply obliterated. Together, these results indicate that the geographic mosaic of coevolution reflects differences not only in pairwise host-parasite interactions but also in sympatric parasite strategies and the interactions between parasites.

\section{Individual slave-maker impacts on host populations}

Both slave-maker species in our study imposed relatively harsh consequences on their individual host populations, although the rate, degree, and quality of
FIG. 7. Effect of slave-maker presence on cumulative host colony movement, based on the 2004 census period. When T. duloticus had exclusive access, nearly $70 \%$ of host colonies relocated within two weeks of being placed in enclosures. Movement by hosts in the other treatment groups was less frequent.

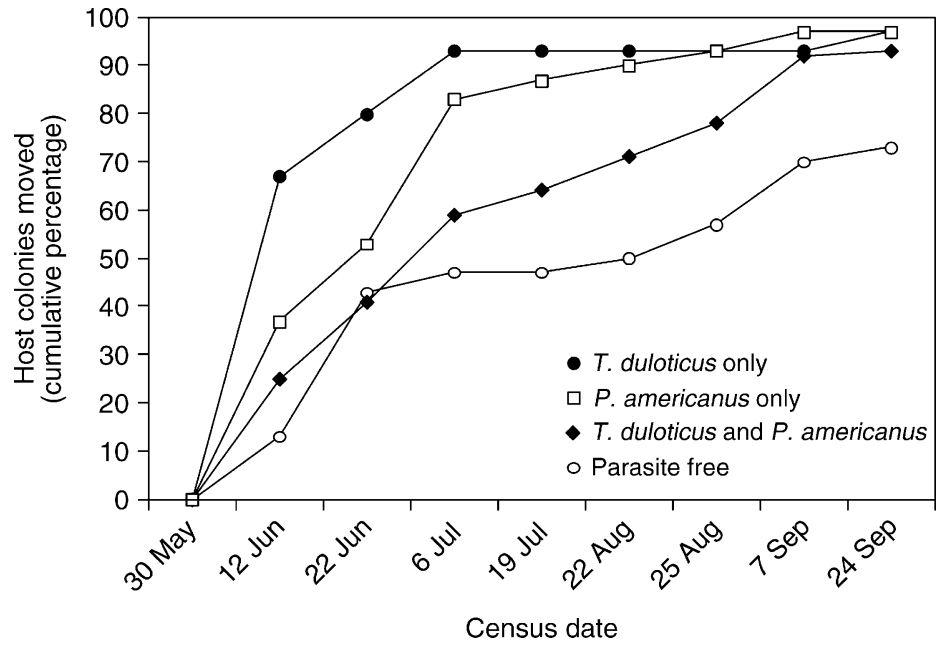


host damage by each slave-maker species differed dramatically (Figs. 3, 4, 7). The congener T. duloticus was clearly more destructive, invading occupied and unoccupied nest sites almost immediately, whereas $P$. americanus seemed restricted to occupying only empty nest sites (Table 3). Host colonies in these single-parasite enclosures moved more often and had substantially lower survivorship than those in single-parasite enclosures with $P$. americanus. Multiple-queen host colonies also tended to fractionate in response to $T$. duloticus, indicating host colonies responded differentially to slave-maker species (Fig. 4). By summer's end, T. duloticus had plundered its enclosure host populations to extinction (Fig. 3), whereas host colonies in single-parasite $P$. americanus enclosures persisted. The subsequent complete disappearance of T. duloticus in three of these enclosures suggests that such aggressive over-exploitation can lead to local parasite extinctions. Indeed in natural sites where $T$. duloticus was prevalent, the number of host colonies was frequently low, whereas in sites with high numbers of $P$. americanus, large numbers of host colonies were always available (C. Johnson, unpublished data). These results are entirely consistent with previous findings (Wesson 1939, 1940, Alloway 1979, Stuart and Alloway 1985) that implicate relative prudence in host use by $P$. americanus as compared to T. duloticus (Hare and Alloway 2001) and clearly demonstrate higher probabilities for long-term survival as a result of prudence when slavemakers are allopatric. The omnipresent distribution of $P$. americanus across its host species range in contrast with local patchiness of T. duloticus (Talbot 1957) suggest $T$. duloticus is governed by cycles of site invasion and rapid over-exploitation of hosts, which eventually leads to local extinction, whereas relative prudence enables $P$. americanus to recover from short-lived collapse (Holmes 1988).

\section{Nonadditive effects: evidence of interference competition?}

Parasite as well as host populations can be severely affected by extreme parasite virulence and rapid exploitation. Consequently, there is often strong selection for prudent forms of the parasite to sustain future host supplies (Frank 1998) and, ultimately, parasite fitness. Studies comparing $P$. americanus and host behaviors across numerous geographical locations indicate an evolutionary trajectory leading towards prudence (Foitzik et al. 2001, Herbers and Foitzik 2002). Nonetheless, both $P$. americanus and $T$. duloticus are completely dependent on their hosts for survival and must replenish or augment their supply yearly during a narrow time period. The retarded decline of host colonies in enclosures with both slave-makers was, therefore, quite unexpected (Fig. 3). Concentrated interactions between multiple predators have been shown to sometimes provide shared prey with ecological refuges (Polis et al. 1989; for a review, see Sih et al. 1998). The results here indicate that the reduced slave-maker impact on the host population may be a function of the same. Raids of $P$. americanus and $T$. duloticus are rarely if ever observed in the field due to the small physical stature of these ants and colony sizes (Alloway 1980). Our field observations of two T. duloticus colonies raiding colonies of $P$. americanus and $T$. curvispinosus in field enclosures just days after being placed in sympatry are, therefore, highly suggestive. Combined with the accelerated loss of $P$. americanus colonies in mixed-parasite enclosures (Fig. 5e-h), it seems clear that the delayed impact on the host populations is due partly to aggressive interactions between $P$. americanus and T. duloticus that reflect either direct competition or outright social hyperparasitism stemming from primordial territorial tendencies of ancestral species (Wilson 1971, 1975, Alloway 1979, 1980, Alloway et al. 1982). Furthermore, it is clear that the interactions were qualitatively and quantitatively asymmetrical, exceeding mere differences in slave-maker numbers. The root of these competitive asymmetries can be traced to the disparate evolutionary histories (Beibl et al. 2005) and dynamics of the two slave-maker species (e.g., Wesson 1939, 1940, Alloway 1979, Stuart and Alloway 1985, Hare and Alloway 2001), which may render prudent behavior beneficial in populations with little interspecific parasite competition but disadvantageous in areas with an aggressive competitor. In host species under heavy single parasite pressure, there is a shift in reproductive allocation towards the production of sexuals (Foitzik and Herbers 2001b), and future investigations may reveal that under heavy parasite competition, other slave-makers may increase sexual production as a means to colonize new patches.

\section{Asymmetric competition and the geographic mosaic of coevolution}

Qualitative or quantitative asymmetries in competitive ability can produce a cascade of effects that lead to significant changes in species distribution, biodiversity, and local community structure (Law and Watkinson 1989, Hudson and Greenman 1998). Parasitism is increasingly recognized as an important factor in generating these changes (Minchella and Scott 1991, Poulin 1999, Mouritsen and Poulin 2002), and competition between parasites plays a major role in modifying host-use patterns (MacArthur 1972, Poulin 1998). Our study is the first to examine interspecific competition of social parasites, and demonstrates that asymmetrical antagonistic interactions (Fig. 6) may drive the inverse relationship in relative frequencies (Fig. 2) and local checkered distributions of the two slave-maker species. Slave-makers were never interspersed, although both were broadly sympatric in approximately half of our field sites. Instead, microsites contained either $P$. americanus or $T$. duloticus even though sometimes these microsites were separated by only a few meters. The spatial disjunction within a 
ubiquitous distribution of hosts is indicative of interspecific parasite aggressive interactions. Together our observations indicate that $T$. duloticus may exclude $P$. americanus from local patches, ultimately leaving host populations to bear only one slave-maker species.

Whereas extrinsic factors typically lead to restrictive niche partitioning for microparasites that live in the same host species (Rohde 1979), the converse may be true for social parasites because of the ability to actively disperse in response to intraguild parasite pressure. Thus, the consequences of facilitated or active dispersal in a tripartite coevolutionary arms race are potentially ratcheting as the combination of available hosts and alternative parasites, upon which local coevolutionary dynamics hinge, becomes relatively fluid. In effect, selection pressures that each slave-maker exerts on shared hosts as a function of the interactions between parasites provide a precondition for the geographic mosaic of coevolution.

\section{Conclusions}

Evolutionary interactions between any parasite and host species are a function of local ecological selection pressures, and community composition can significantly impact host-parasite relationships (Bonsall and Hassell 1997). Our two-social-parasite-one-host system provided us the opportunity to directly examine natural tripartite coevolutionary dynamics. We show that variation in slave-maker presence differentially impacts a shared host and suggest that by affecting realized selection pressures, intra-guild interactions of social parasites may be a prime contributor to the mosaic of coevolutionary hot and cold spots across geographic sites.

\section{ACKNOWLEDGMENTS}

We are grateful to the Metro Parks of Columbus, Ohio (John O'Meara, Director), Ohio Wesleyan University, and the late Dr. John Kraus for permission to work in their preserves. We thank G. Buzchowski, S. Farkas, C. Kwapich, S. O’Brien, and J. Roe for assistance in the field. We also thank Sean Collins and Johannes Foufopoulos for comments on an early version of this manuscript. We also thank two anonymous reviewers for their comments. This study was supported by a grant to J. M. Herbers from the National Science Foundation.

\section{Literature Cited}

Alloway, T. M. 1979. Raiding behaviour of two species of slave-making ants, Harpagoxenus americanus (Emery) and Leptothorax duloticus Wesson (Hymenoptera: Formicidae). Animal Behavior 27:202-210.

Alloway, T. M. 1980. The origins of slavery in Leptothoracine ants (Hymenoptera: Formicidae). American Naturalist 115:247-261.

Alloway, T. M., A. Buschinger, M. Talbot, R. Stuart, and C. Thomas. 1982. Polygyny and polydomy in three North American species of the ant genus Leptothorax Mayr (Hymenoptera: Formicidae). Psyche 89:249-274.

Anderson, R. M., and R. M. May. 1991. Infectious diseases of humans: dynamics and control. Oxford University Press, Oxford, UK.
Beibl, J., R. J. Stuart, J. Heinze, and S. Foitzik. 2005. Six origins of slavery in formicoxenine ants. Insectes Sociaux 52:291-297.

Benkman, C. W. 1999. The selection mosaic and diversifying coevolution between crossbills and lodgepole pine. American Naturalist 163:S75-S91.

Benkman, C. W., W. C. Holimon, and J. W. Smith. 2001. The influence of a competitor on the geographic mosaic of coevolution between crossbills and lodgepole pine. Evolution 55:282-294.

Benkman, C. W., T. L. Parchman, A. Favis, and A. M. Siepielski. 2003. Reciprocal selection causes a coevolutionary arms race between crossbills and lodgepole pine. American Naturalist 162:182-194.

Blatrix, R., and J. M. Herbers. 2003. Coevolution between slave-making ants and their hosts: host specificity and geographical variation. Molecular Ecology 12:2809-2816.

Bolton, B. 2003. Synopsis and classification of Formicidae. Memoirs of the American Entomological Institute 71:1370.

Bonsall, M. B., and M. P. Hassell. 1997. Apparent competition structures ecological assemblages. Nature 388:371373.

Brandt, M., and S. Foitzik. 2004. Community context and specialization influence coevolution between a slavemaking ant and its hosts. Ecology 85:2997-3009.

Buschinger, A. 1986. Evolution of social parasitism in ants. Trends in Ecology and Evolution 1:155-160.

Davies, N. B., A. F. G. Bourke, and M. D. L. Brooke. 1989. Cuckoos and parasitic ants: interspecific brood parasitism as an evolutionary arms race. Trends in Ecology and Evolution 4:274-278.

Dawkins, R., and J. R. Krebs. 1979. Arms races between and within species. Proceedings of the Royal Society of London, Series B 202:489-511.

Emery, C. 1909. Über den Ursprung der dulotischen, parasitischen und myrmekophilen Ameisen. Biologisches Zentralblatt 29:352-362.

Foitzik, S., C. J. deHeer, D. N. Hunjan, and J. M. Herbers. 2001. Coevolution in host-parasite systems: behavioural strategies of slave-making ants and their hosts. Proceedings of the Royal Society of London, Series B 268:1139-1146.

Foitzik, S., B. Fischer, and J. Heinze. 2003. Arms races between social parasites and their hosts: geographic patterns of manipulation and resistance. Behavioral Ecology and Sociobiology 14:80-88.

Foitzik, S., and J. M. Herbers. 2001a. Colony structure of a slavemaking ant. I. Intracolony relatedness, worker reproduction, and polydomy. Evolution 55:307-315.

Foitzik, S., and J. M. Herbers. 2001b. Colony structure of a slavemaking ant. II. Frequency of slave raids and impact on host population. Evolution 55:316-323.

Frank, S. A. 1998. Models of parasite virulence. Quarterly Review of Biology 71:37-78.

Gandon, S. 2004. Evolution of multihost parasites. Evolution. 58:455-469.

Gandon, S., and Y. Michalakis. 2002. Local adaptation, evolutionary potential and host-parasite coevolution: interactions between migration, mutation, population size and generation time. Journal of Evolutionary Biology 15:451462.

Gladstone, D. E. 1981. Why there are no ant slave rebellions. American Naturalist 117:779-781.

Gomulkiewicz, R., J. N. Thompson, R. D. Holt, S. L. Nuismer, and M. E. Hochbergs. 2000. Hot spots, cold spots, and the geographic mosaic theory of coevolution. American Naturalist 156:156-174.

Hare, J. F., and T. M. Alloway. 2001. Prudent Protomognathus and despotic Leptothorax duloticus: differential costs 
of ant slavery. Proceedings of the National Academy of Sciences (USA) 98:12093-12096.

Herbers, J. M. 1986. Effects of ecological parameters on queen number in Leptothorax longispinosus (Hymenoptera: Formicidae). Journal of the Kansas Entomological Society 59:675-686.

Herbers, J. M., and S. Foitzik. 2002. The ecology of slavemaking ants and their host in north temperate forests. Ecology 83:148-163.

Herbers, J. M., and R. J. Stuart. 1998. Patterns of reproduction in slave-making ants. Proceedings of the Royal Society of London, Series B 265:875-887.

Holmes, J. C. 1988. Evolutionary relationships between parasitic helminthes and their hosts. Pages 161-185 in D. J. Futuyma and M. Slatkin, editors. Coevolution. Sinauer Associates, Sunderland, Massachusetts, USA.

Hölldobler, B., and E. O. Wilson. 1990. The ants. Harvard University Press, Cambridge, Massachusetts, USA.

Holt, R. D., and J. H. Lawton. 1994. The ecological consequences of shared natural enemies. Annual Review of Ecology and Systematics 25:495-520.

Hudson, P., and J. Greenman. 1998. Competition mediated by parasites: biological and theoretical progress. Trends in Ecology and Evolution 13:387-390.

Kawecki, T. J. 1994. Accumulation of deleterious mutations and the evolutionary cost of being a generalist. American Naturalist 144:833-838.

Kawecki, T. J. 1998. Red queen meets Santa Rosalia: arms races and the evolution of host specialization in organisms with parasitic lifestyles. American Naturalist 152:635-651.

Law, R., and A. R. Watkinson. 1989. Competition. Pages 243-284 in J. M. Cherrett, editor. Ecological concepts: the contribution of ecology to an understanding of the natural world. 29th Symposium of the British Ecological Society. Blackwell Scientific Press, London, UK.

Lotem, A., and S. I. Rothstein. 1995. Cuckoo-host coevolution: from snap-shots of an arms race to the documentation of coevolution. Trends Ecology and Evolution 10: 436-437.

MacArthur, R. H. 1972. Geographical ecology. Patterns in the distribution of species. Harper and Row, New York, New York, USA.

Minchella, D. J., and M. E. Scott. 1991. Parasitism: a cryptic determinant of animal community structure. Trends in Ecology and Evolution 6:250-254.

Mouritsen, K. N., and R. Poulin. 2002. Parasitism, climate oscillations and the structure of natural communities. Oikos 97:462-468.

Polis, G. A., C. A. Myers, and D. Holt. 1989. The ecology and evolution of intraguild predation: potential competitors that eat each other. Annual Review of Ecology Systematics 20:297-330.

Poulin, R. 1998. Evolutionary ecology of parasites, from individuals to communities. Chapman and Hall, New York, New York, USA.
Poulin, R. 1999. The functional importance of parasite in animal communities: many roles at many levels? International Journal for Parasitology 29:903-914.

Price, P. W. 1980. Evolutionary biology of parasites. Princeton University Press, Princeton, New Jersey, USA.

Rohde, K. 1979. A critical evaluation of intrinsic and extrinsic factors responsible for niche restriction in parasites. American Naturalist 114:648-671.

Rothstein, S. I. 1990. A model system for coevolution: avian brood parasitism. Annual Review of Ecology and Systematics 21:481-508.

Rothstein, S. I., and S. K. Robinson. 1994. Conservation and coevolutionary implications of brood parasitism by cowbirds. Trends in Ecology and Evolution 9:162-164.

Siddon, C. E., and J. D. Witman. 2003. Behavioral indirect interactions: multiple predator effects and prey switching in the rocky subtidal. Ecology 85:2938-2945.

Sih, A., G. Englund, and D. Wooster. 1998. Emergent impacts of multiple predators on prey. Trends in Ecology and Evolution 13:350-355.

Stuart, R. J., and T. M. Alloway. 1985. Behavioural evolution and domestic degeneration in obligatory slave-making ants (Hymenoptera: Formicidae: Leptothoracini). Animal Behavior 33:1080-1088.

Talbot, M. 1957. Population studies of the slave-making ant Leptothorax duloticus and its slave, Leptothorax curvispinosus. Ecology 38:449-456.

Thompson, J. N. 1994. The coevolutionary process. University of Chicago Press, Chicago, Illinois, USA.

Thompson, J. N. 1997. Evaluating the dynamics of coevolution among geographically structured populations. Ecology 78:1619-1623.

Thompson, J. N. 1999. Specific hypotheses on the geographic mosaic of coevolution. American Naturalist 153:S1-S14.

Thompson, J. N., and O. Pellmyr. 1992. Mutualism with pollinating seed parasites amid copollinators: constraints on specialization. Ecology 73:1780-1791.

Van Valen, L. 1973. A new evolutionary law. Evolutionary Theory 1:1-30.

Wesson, L. G. 1939. Contributions to the natural history of Harpagoxenus americanus. Transactions of the American Entomological Society 65:97-122.

Wesson, L. G. 1940. Observations on Leptothorax duloticus. Bulletin of the Brooklyn Entomological Society 35:73-83. Whitlock, M. C. 1996. The Red Queen beats the Jack-of-alltrades: the limitations on the evolution of phenotypic plasticity and niche breadth. American Naturalist 148:S65-S77.

Wilson, E. O. 1971. The insect societies. Belknap Press, Cambridge, Massachusetts, USA.

Wilson, E. O. 1975. Leptothorax duloticus and the beginnings of slavery in ants. Evolution 29:108-119.

Wissinger, S., and J. McGrady. 1993. Intraguild predation and competition between larval dragonflies: direct and indirect effects on shared prey. Ecology 74:207-218.

\section{APPENDIX}

Tukey's post-hoc comparisons of the proportion of queenless, monogyne, and polygyne colonies in enclosures (Ecological Archives E087-022-A1). 